\title{
Ordering Designee
}

National Cancer Institute

\section{Source}

National Cancer Institute. Ordering Designee. NCI Thesaurus. Code C54656.

The person who is designated by the Investigator to order investig ational agents on his/her behalf. 